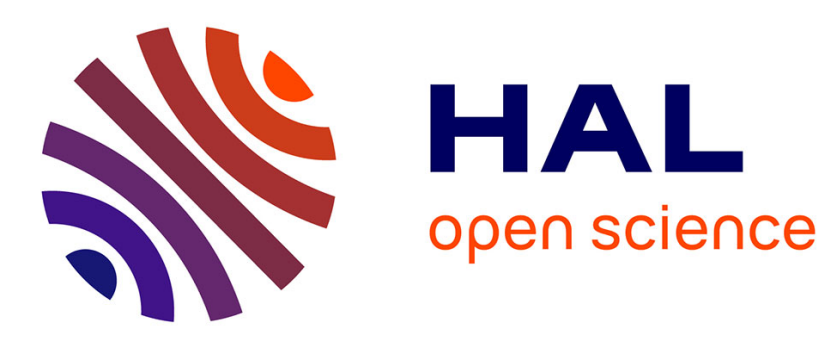

\title{
Impedance Spectroscopy Failure Diagnosis of a DFIG-Based Wind Turbine
}

Mohamed Becherif, A. Henni, Mohamed Benbouzid, Maxime Wack

\section{To cite this version:}

Mohamed Becherif, A. Henni, Mohamed Benbouzid, Maxime Wack. Impedance Spectroscopy Failure Diagnosis of a DFIG-Based Wind Turbine. IEEE IECON, Oct 2012, Montreal, Canada. pp.4310-4315. hal-00768839

\section{HAL Id: hal-00768839 \\ https://hal.science/hal-00768839}

Submitted on 25 Dec 2012

HAL is a multi-disciplinary open access archive for the deposit and dissemination of scientific research documents, whether they are published or not. The documents may come from teaching and research institutions in France or abroad, or from public or private research centers.
L'archive ouverte pluridisciplinaire HAL, est destinée au dépôt et à la diffusion de documents scientifiques de niveau recherche, publiés ou non, émanant des établissements d'enseignement et de recherche français ou étrangers, des laboratoires publics ou privés. 


\title{
Impedance Spectroscopy Failure Diagnosis of a DFIG-Based Wind Turbine
}

\author{
Mohamed Becherif, Assia Henni, Mohamed Benbouzid and Maxime Wack
}

\begin{abstract}
Wind turbines proliferation in industrial and residential applications is facing the problem of maintenance and fault diagnosis. Periodic maintenances are necessary to ensure an acceptable life span. The aim of this work is to develop theoretical tools to diagnose the failure or the malfunction of the doubly-fed induction generator (DFIG). The diagnosis method is based on the impedance spectroscopy which is used for the diagnosis of batteries, fuel cells, and electrochemical systems. This first attempt for using this method to the diagnosis of the DFIG provides good results for the detection of the grounding connection, short circuit and stator resistance variation.
\end{abstract}

Index Terms-Wind turbine, doubly-fed induction generator, failure diagnosis, impedance spectroscopy.

\section{INTRODUCTION}

France is the Europe's second potential source of wind power, behind the UK. Areas are very windy on the west side of the country, the Vendée in Pas-de-Calais, Rhone Valley and the Languedoc coast. Wind patterns are different in these three areas, making them complementary to each other (Fig. 1.).

Wind is variable locally. Its speed may be zero, too weak or too strong and in this case wind turbines can't produce electricity.

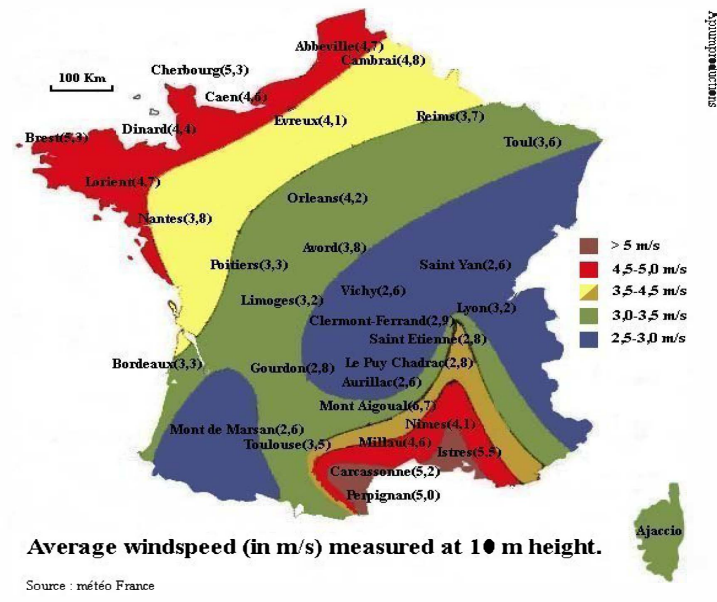

Fig. 1. France wind speed map [1].

\footnotetext{
M. Becherif is with UTBM University, FCLab FR CNRS 3539, FEMTOST UMR CNRS 6174, 90010 Belfort, France (email: Mohamed.Becherif@utbm.fr).

A. Henni is with UTBM University, 90010 Belfort, France (email: Assia.Henni@utbm.fr).

M.E.H Benbouzid is with the University of Brest, EA 4325 LBMS, Rue de Kergoat, CS 93837, 29238 Brest, France (e-mail: Mohamed.Benbouzid@univ-brest.fr).

M. Wack is with UTBM University, FCLab FR CNRS 3539, 90010 Belfort, France (email: Maxime.Wack@utbm.fr).
}

However, these local effects can be mitigated: 1) Given the different weather patterns in a given regions, wind power is not zero at the same time; 2) The winds are more common in winter when electricity demand is highest.

The advantages of using wind farm are: 1) Renewable energy: The wind is renewable, and thus the $\mathrm{kWh}$ produced from wind power are saving the limited resources of the planet's oil, gas, coal and uranium. Wind power certainly contributes to sustainable development. 2) Releases: Wind is a clean energy and no rejection is produced. 3) Greenhouse effect: The wind does not produce any greenhouse gases other than that due to the manufacture of the materials used (cement, steel, etc.). This explains its popularity in countries like Denmark and Germany, two major European producers of $\mathrm{CO}_{2}$.

The disadvantages are: 1) Noise: Significant progress in terms of noise. The sound generated is less audible $(45 \mathrm{~dB}$ at $300 \mathrm{~m}$ for the latest machine generations). 2) Radio interference: The rotation of the propeller interferes with radio waves. 3) Birds: The ribs are traditional migration routes, and the rotating blades of the propellers are a danger to migratory birds (the peripheral speed of the blades can reach $300 \mathrm{~km} / \mathrm{h}$ ). 4) Strobe effect: Several associations complain that the propeller blades hiding the sun on a slow and steady over time may have serious psychological impact on local residents. 5) Decommissioning: The holding of poles can exceed $100 \mathrm{~m}$ in height and requested by the wind acting on gigantic blades requires the establishment of bases of several hundred tons of reinforced concrete driven into the ground.

\section{Wind TURBINE FAULT DiAgNOSIS OVERVIEW}

A quantitative analysis of real wind turbine failure data has shown important features of failure rate values and trends.

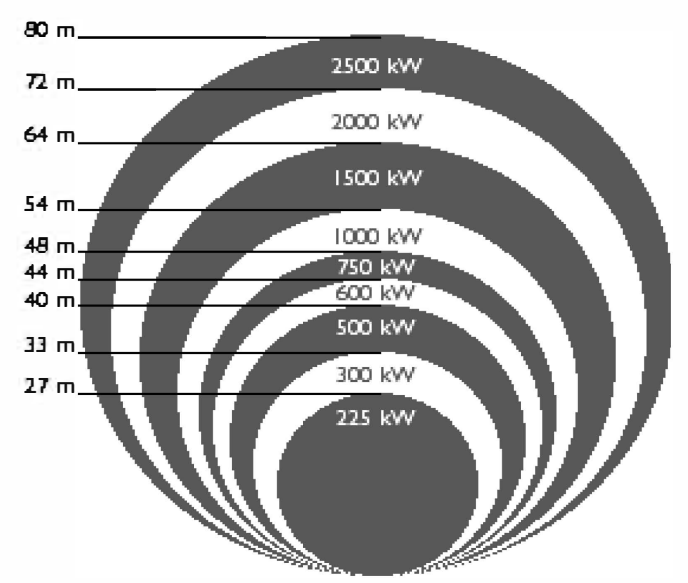

Fig. 2. Wind turbine power as function of the blade diameters. 
A failures number distribution check-off is reported in Fig. 3 for Swedish, Danish and German wind power plants that occurred between 1994 and 2004 [2]. These figures show that approximately $45 \%$ of failures were linked to the electrical system, sensors and blades/pitch components. The experience feedback of wind turbine industries states that the major concern is on the electrical system. Typical failures include: dynamic air gap irregularities, generator bearing failure, stator and rotor winding; insulation failures, inter-turn short circuits in stator windings, broken rotor bar or cracked rotor end-rings and harmonic degrading.

DFIG failure diagnosis is becoming an active area of research and many papers are devoted to this topic [3-6].

\section{THE DOUBLY-FED INDUCTION GENERATOR}

Classical generator with short-circuit rotor terminals or squirrel-cage is only able to have a minimal rotor speed variation (10\% approximately). A DFIG allows a variation of the rotor speed from $-40 \%$ to $+30 \%$ of the generators synchronous speed, which increases the yearly production by approximately $5 \%$.

DFIG system has a converter connected to the rotor.

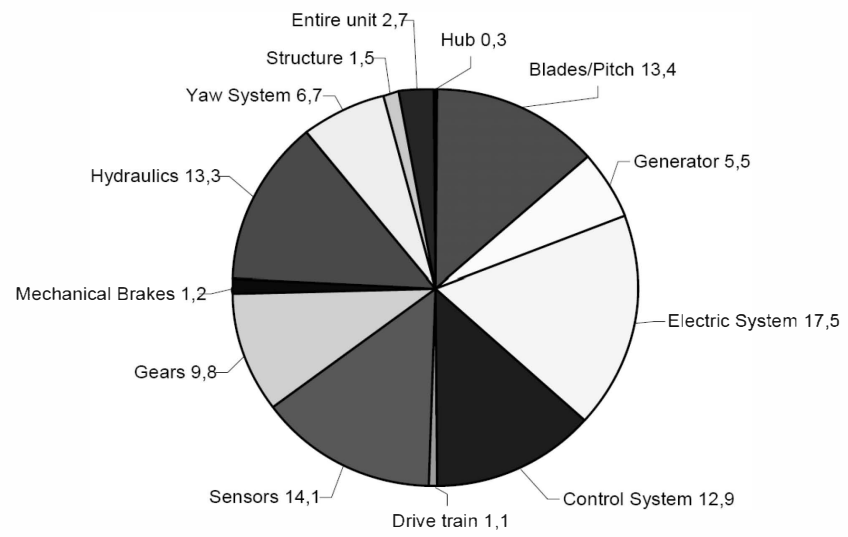

(a) Failures number distribution for Swedish wind power plants (2000-2004).

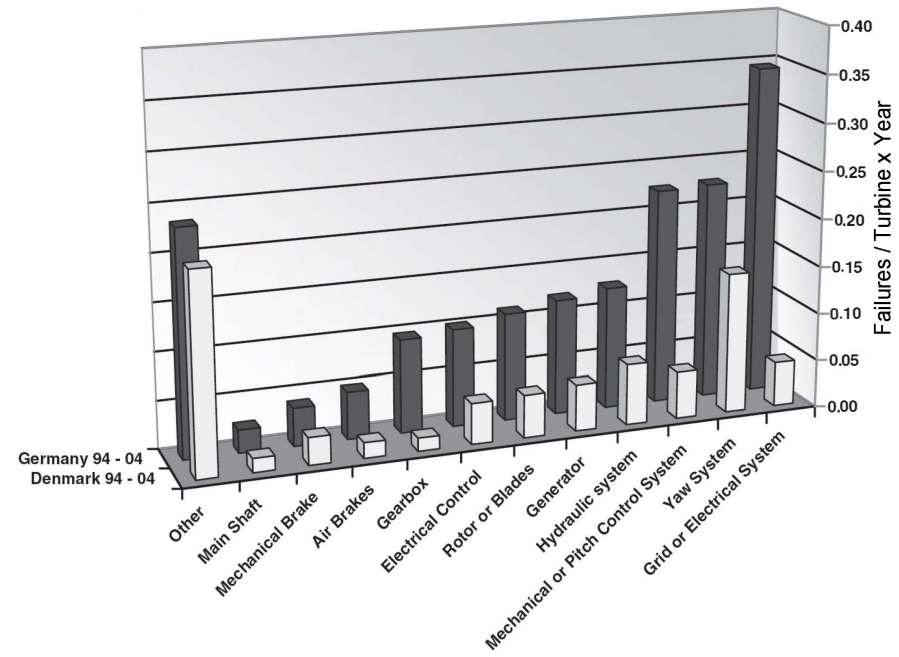

(b) Failure rates for Danish and German wind power plants.

Fig. 3. Wind turbine failure rates [2].
The converter makes it possible to supply or obtain power from the grid through the rotor terminals. This prevents the generator from switching to motor operation while driving at sub synchronous speed. In the so called over synchronous operation the generator's speed is higher than synchronous speed. In this operation power from the stator terminals as well as power from the rotor terminals is supplied to the grid. The DFIG basic schematic is shown by Fig. 4 and its equivalent circuit by Fig. 5 [7].

The DFIG modeling is done in the $d-q$ frame and is not presented in this paper.

The power is controlled in order to follow a pre-defined power-speed characteristic, named tracking characteristic. The power control loop is illustrated by Fig. 6 . The actual electrical output power, measured at the grid terminals of the wind turbine, is added to the total power losses (mechanical and electrical) and is compared with the reference power obtained from the tracking characteristic.

A classical flux-oriented control is applied combined with a power maximization technique and control of the active and reactive powers. A PI controller is used to reduce the power error to zero. The output of this controller is the reference rotor current $I_{q r_{-} \text {ref }}$ that must be injected in the rotor by the $C_{\text {rotor }}$ converter. This current component produces the electromagnetic torque $T_{e m}$. The actual $I_{q r}$ component of positive-sequence current is compared to $I_{q r}$ ref and the error is reduced to zero by a PI current controller. The output of this current controller is the voltage $V_{\text {ar }}$ generated by $C_{\text {rotor }}$. The current controller is assisted by feed forward terms which predict $V_{q}$. The voltage or the reactive power at grid terminals is controlled by the reactive current flowing in the converter. The generic control loop is illustrated by Fig. 7. The active power drawn from the supply maintains the DC bus voltage at a constant value and is controlled by the supply currents $I_{d c}, I_{d g c}$, and $I_{q g c}$. The control procedure is not detailed here for conciseness.

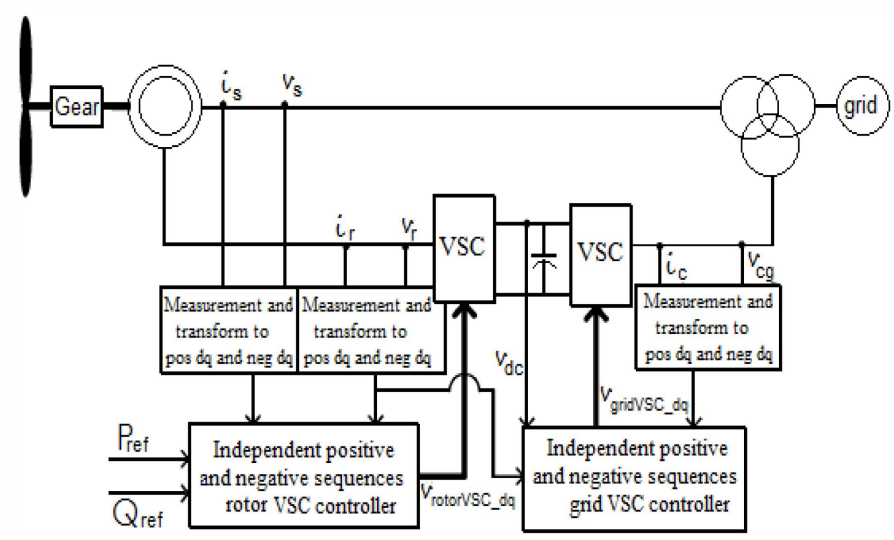

Fig. 4. DFIG schematic.

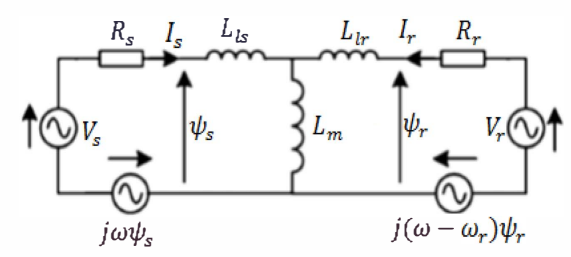

Fig. 5. DFIG equivalent circuit 


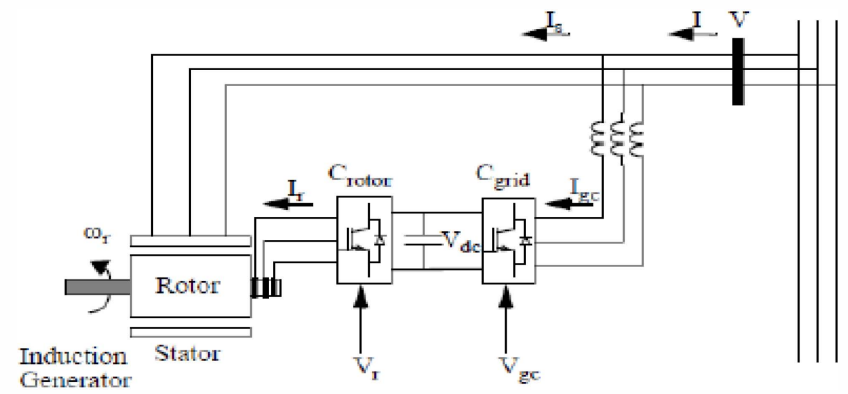

a) rotor-side and grid-side converters

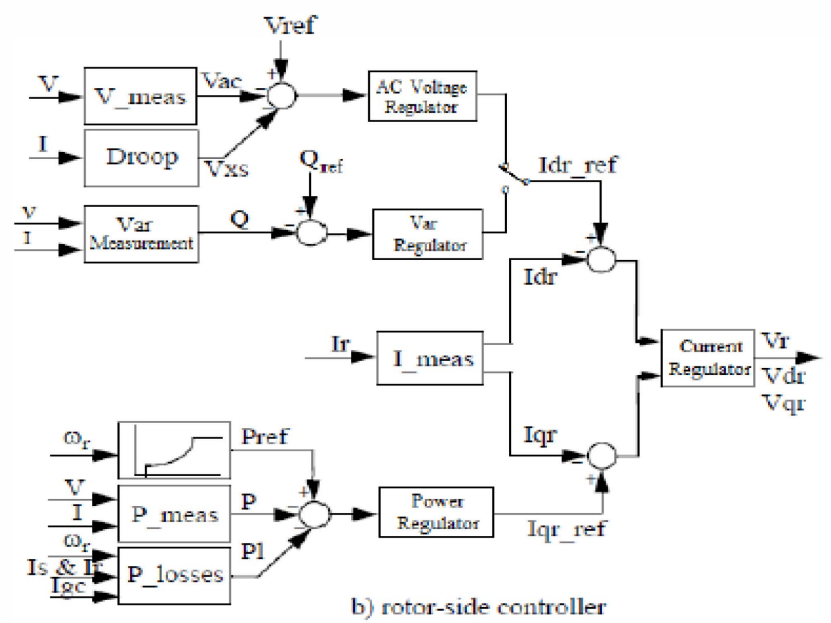

Fig. 6. Rotor-side converter system [7].

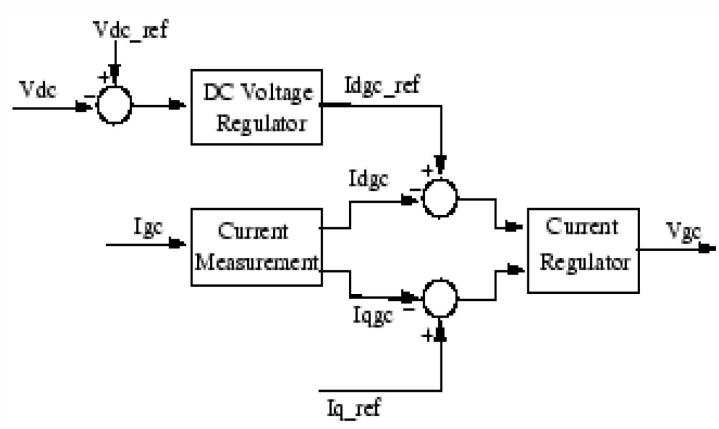

Fig. 7. Grid-side converter system [7].

\section{IMPEDANCE SPECTROSCOPY}

Impedance Spectroscopy (IS) is a general term that subsumes the small-signal measurement of the linear electrical response of a material of interest (including electrode effects) and the subsequent analysis of the response to yield useful information about the physico-electrochemical properties of the system (Fig. 8). Analysis is generally carried-out in the frequency domain, although measurements are sometimes made in the time-domain and then Fourier transformed to the frequency domain, see [8-11] for an in-depth review.

The electrical resistance is the ability of a circuit element to resist the flow of electrical current. Ohm's law defines resistance in terms of the ratio between voltage $E$ and current I.

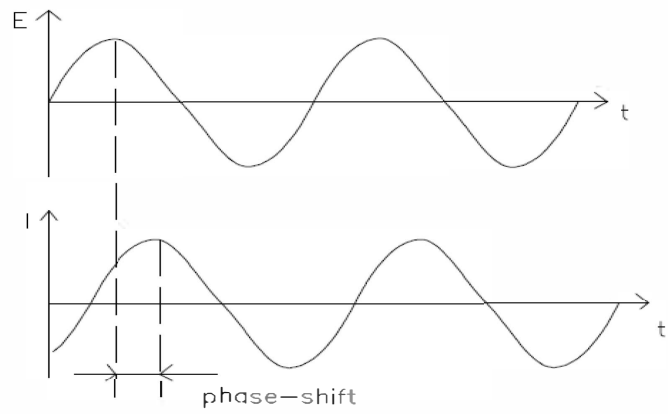

Fig. 8. Sinusoidal current response in a linear system.

$R=\frac{E}{I}$

While this is a well-known relationship, its use is limited to only one circuit element (the ideal resistor). An ideal resistor has several simplifying properties: It follows Ohm's law at all current and voltage levels; its resistance value is independent of frequency; $\mathrm{AC}$ current and voltage signals through a resistor are in phase with each other. Industry applications contain circuit elements with more complex behavior, and then impedance is used instead of resistance. Like resistance, impedance is a measure of the ability of a circuit to resist the flow of electrical current. Unlike resistance, impedance is not limited by the simplifying properties above-listed.

Electrochemical or electrical impedance is usually measured by applying an $\mathrm{AC}$ potential to an element and measuring the current through it. Applying a sinusoidal potential excitation leads to an AC current signal response. This current signal can be analyzed as a sum of sinusoidal functions (Fourier series).

Electrochemical Impedance is normally measured using a small excitation signal. This is done so that the system's response is pseudo-linear. In a linear (or pseudo-linear) system, the current response to a sinusoidal potential will be a sinusoid at the same frequency but phase-shifted in phase (Fig. 8). The excitation signal has the following form

$$
E_{t}=E_{0} \sin \omega t
$$

In a linear system, the response signal $I_{t}$, is phase-shifted and has a different amplitude $I_{0}$.

$$
I=I_{0} \sin (\omega t+\phi)
$$

Figure 9 is the Lissajous representation which describes the system's complex harmonic motion. When the input to an LTI (Linear Time Invariant) system is sinusoidal, the output is sinusoidal with the same frequency. An LTI system produces an ellipse. The equivalent Nyquist plot is given by Fig. 10 (for a $1^{\text {st }}$ order system).

Using Euler's relationship

$$
e^{j \phi}=\cos \phi+j \sin \phi
$$

it is possible to express the impedance as a complex function. The potential is described as 


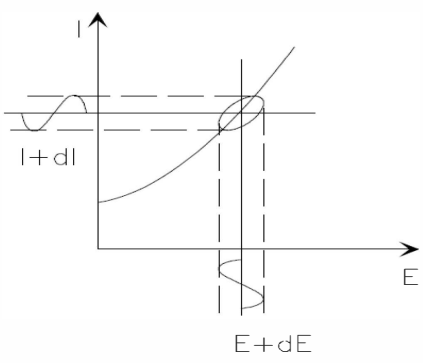

Fig. 9. Lissajous representation.

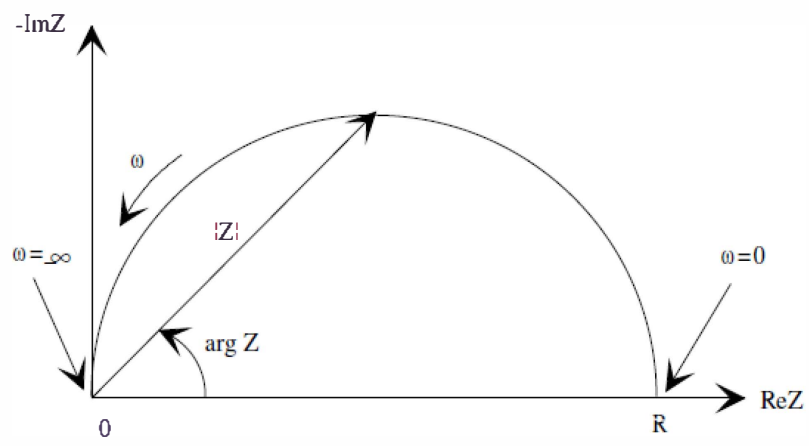

Fig. 10. Nyquist plot with impedance vector.

$E_{t}=E_{0} e^{j \omega t}$

and the current response as

$$
I_{t}=I_{0} e^{j \omega t-\phi}
$$

The impedance is then represented as a complex number

$$
Z(\omega)=\frac{E}{I}=Z_{0} e^{j \phi}=Z_{0}(\cos \phi+j \sin \phi)
$$

The impedance is therefore expressed in terms of a magnitude $Z_{0}$, and a phase shift $\phi$. In Fig. 10, it should be noticed that the $y$-axis is negative and that each point on the Nyquist plot is the impedance at a given frequency. Low frequency data are on the right-side of the plot and higher ones are on the left-side. On the Nyquist plot, the impedance can be represented as a vector of $|Z|$ amplitude. The angle between this vector and the $x$-axis is $\phi(=\arg Z)$.

Nyquist plots have one major shortcoming by considering the frequency as an implicit variable.

Data can be plotted either in the frequency- or in timedomain. A transform can be used to switch between the domains. The Fourier transform takes time-domain data and generates the equivalent frequency-domain data.

\section{IMPEDANCE SPECTROSCOPY-BASED FAILURE DIAGNOSIS}

Different diagnosis techniques were developed during recent years depending on the application domain, among them the IS diagnosis. IS appears destined to play an important role in diagnosis in the coming years. It is the method of choice for characterizing the electrical behavior of systems in which the overall system behavior is determined by a number of strongly coupled processes. With the current availability of commercially made, high-quality impedance bridges and automatic measuring equipment covering the millihertz to megahertz frequency range, it appears certain that impedance studies will become increasingly popular as more and more engineers understand the theoretical basis for IS and gain skill in the interpretation of impedance data.

On the one hand this diagnosis method allows detecting miscellaneous phenomena characterized by spectral impedance analysis. In addition, it allows limiting the overall cost and size of the power transfer unit and monitoring devices. This method allows having the impedance evolutions according to the frequency for a safe case of wind turbine operation and to compare it with that of a faulty case.

Measured signals consist on alternative (real and complex) components (voltage, current and impedance): 1) As a first step, given the use of the static converter, current and voltage ripples are naturally mixed with high frequency noise due to PWM. This noise is totally rejected by choosing a sample frequency adjusted to a division of the PWM frequency. Then the analog digital conversion results in the extraction of desired components of current and voltage ripples. 2) As a second step, complex expression of the current and voltage ripples are calculated by using the Discrete Fourier Transform (DFT) algorithm which gives real and imaginary parts of the measured signals. This method is used to have a good accuracy even if the measured signal presents a residual perturbation. 3) As a third step, spectral impedance is computed from current and voltage, according to the following

$Z(f)=Z(j \omega)=\frac{U(j \omega)}{I(j \omega)}=\bmod [Z(j \omega)] e^{j \arg [Z(j \omega)]}$

where $\left\{\begin{array}{l}U(f)=U(j \omega)=\bmod [U(j \omega)] e^{j \arg [U(j \omega)]} \\ I(f)=I(j \omega)=\bmod [I(j \omega)] e^{j \arg [I(j \omega)]}\end{array}\right.$

Impedance measurement entire process is summarized by Fig. 11.

\section{SiMULATION RESULTS}

A 9-MW wind farm consisting of six 1.5-MW wind turbines connected to a $25-\mathrm{kV}$ distribution system exports power to a $120-\mathrm{kV}$ grid through a $30-\mathrm{km}, 25-\mathrm{kV}$ feeder.

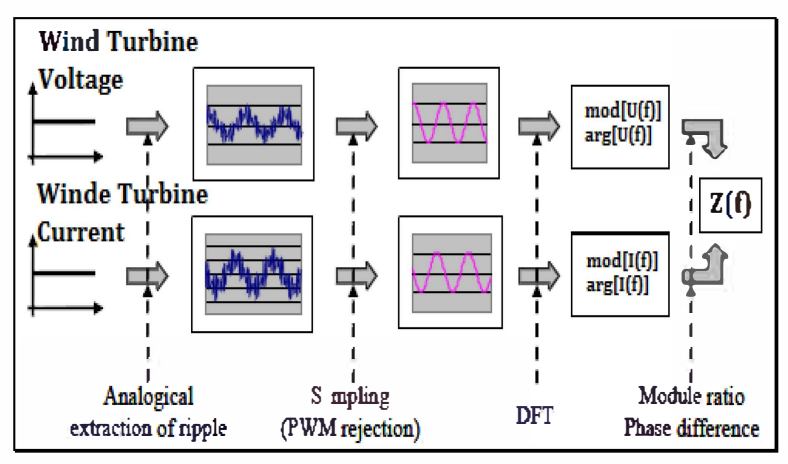

Fig. 11. Impedance measurement functional diagram. 
A 500-kW resistive load and a 0.9-MVAR $(Q=50)$ filter are connected at the $575-\mathrm{V}$ generation bus. Here the wind speed is maintained constant at $10-\mathrm{m} / \mathrm{sec}$. The control system uses a torque controller in order to maintain the speed at 1.09-pu. The reactive power produced by the wind turbine is controlled at 0 MVAR. More simulation parameters can be found in [7].

The goal is to measure the impedance by applying a singlefrequency voltage or current to the studied system. In this case, amplitude and phase shift (or real and imaginary parts) are measured, using either analog circuit or FFT analysis of the response [12]. As the aim is to focus on the DFIG diagnosis, Figs. 12 and 13, gives respectively the Bode and Nyquist diagrams of a healthy DFIG.

Various failures can affect a wind turbine DFIG. In grid codes context, the two frequent failures are phase grounding and phase short-circuits. In addition, DFIG stator resistance variation is also considered for IS diagnosis performance evaluation.

\section{A. Phase Grounding Failure}

Figures 14 and 15 show phase grounding effects on the measured impedance. As it is expected, the measured impedance is equal to zero (Fig. 15).
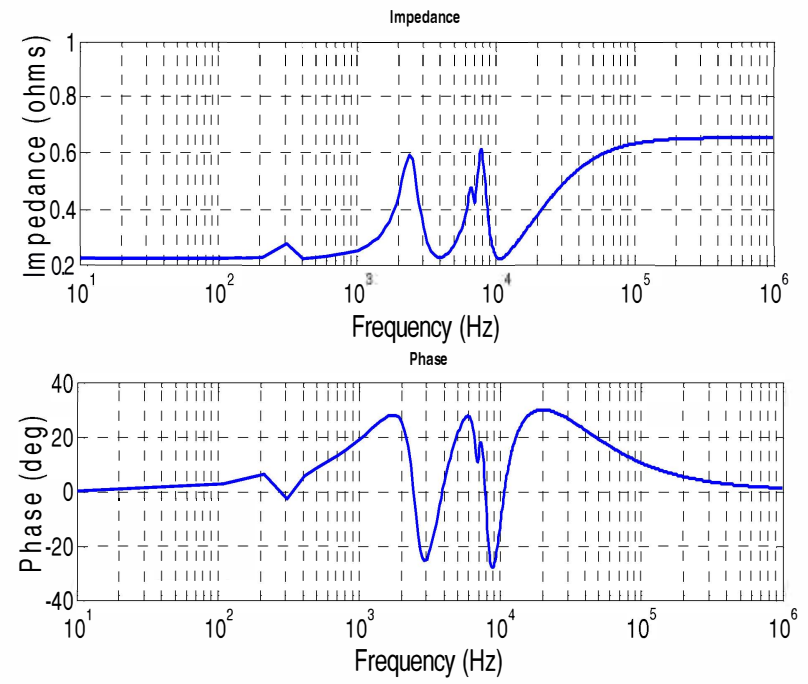

Fig. 12. Bode diagram of a healthy DFIG.

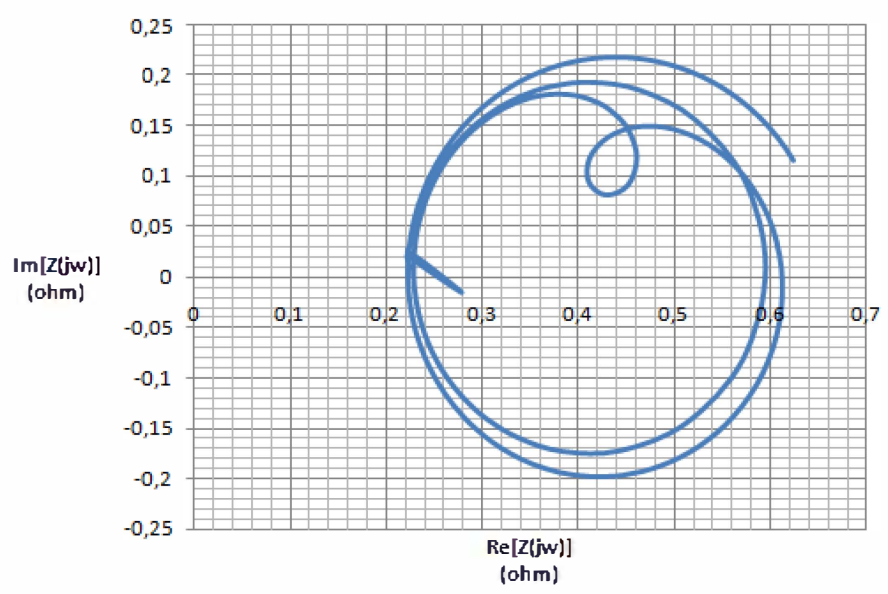

Fig. 13. Nyquist diagram of a healthy DFIG.
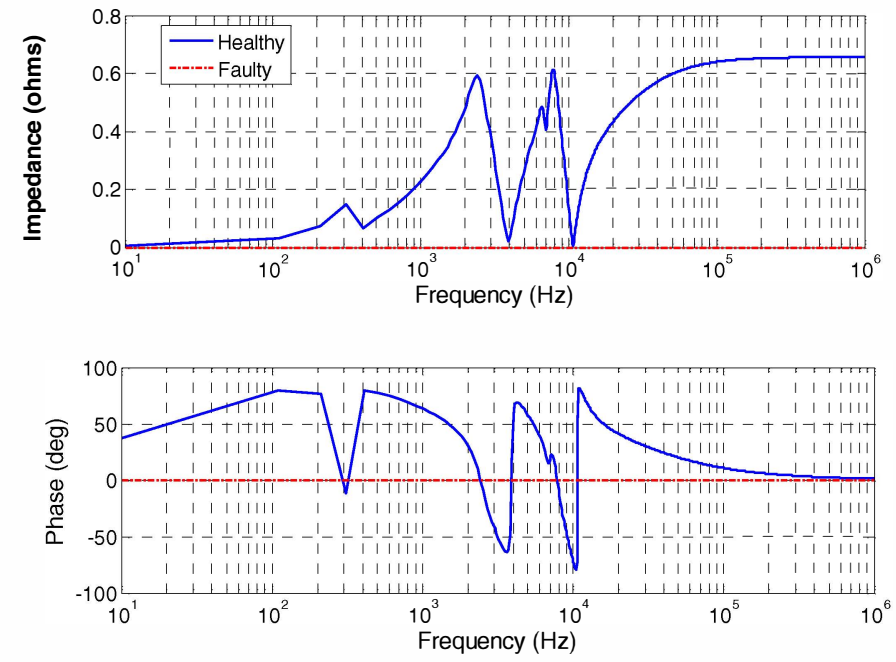

Fig. 14. DFIG Bode diagram with phase grounding

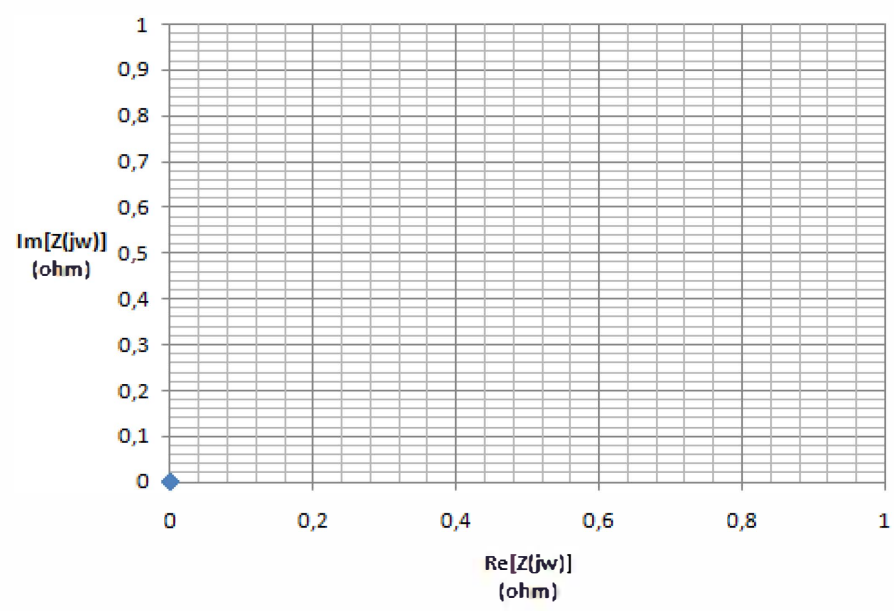

Fig. 15. DFIG Nyquist diagram with phase grounding.

\section{B. Phase Short-Circuits}

In this case, an asymmetrical short-circuit is applied between the DFIG phase A and B. Figure 16 and 17 give respectively Bode and Nyquist impedance plots of phase A (similar results are obtained for phase B).

The faulty curve of Fig. 16 (red dashed line) is below the healthy one as expected. When a short-circuit occurs, the current magnitude increases and consequently the impedance magnitude decreases. In the same time, the current phase increases and consequently the phase decreases.

\section{DFIG Stator Resistance Variation}

A $100 \%$ stator resistance increase, which simulates temperature effect, is considered.

This particular failure can be easily detected thanks to the DFIG magnitude Bode diagram (Fig. 18). The stator resistance variation induces a constant offset over the whole frequency range. The Nyquist diagram (Fig. 19) shows that the imaginary part of the impedance is equal to that of the healthy DFIG, while the real parts are different. This result clearly indicates that parameter variation is a resistance one and not an inductance one. 

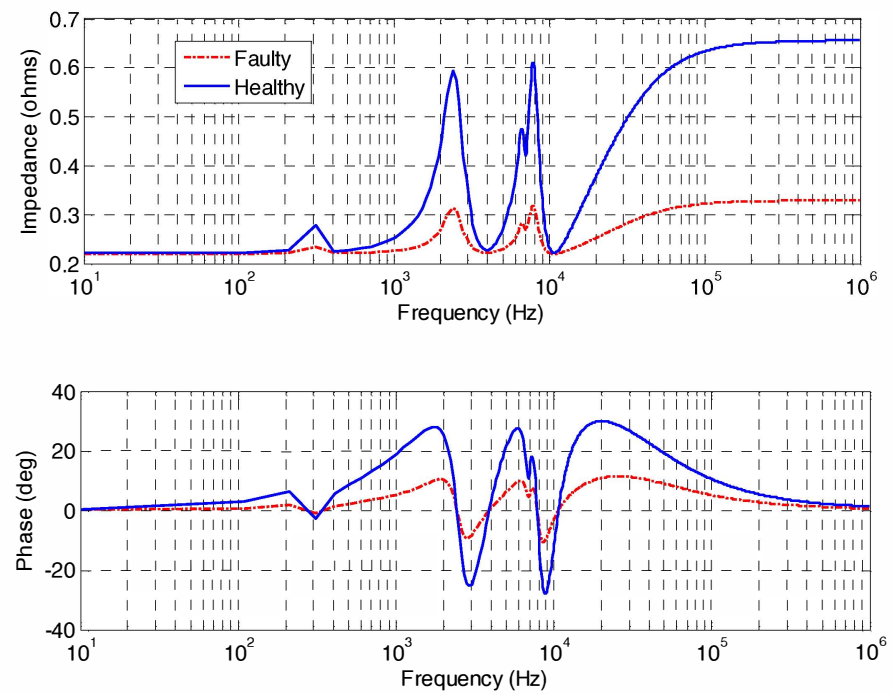

Fig. 16. DFIG Bode diagram with phase short-circuit (between phases A and B).

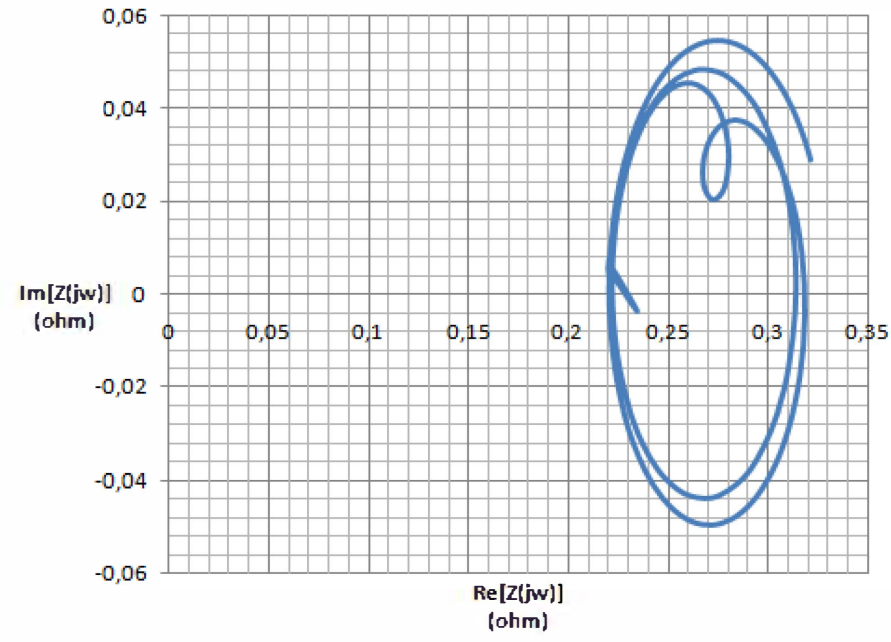

Fig. 17. DFIG Nyquist diagram with phase short-circuit (between phases A and B).
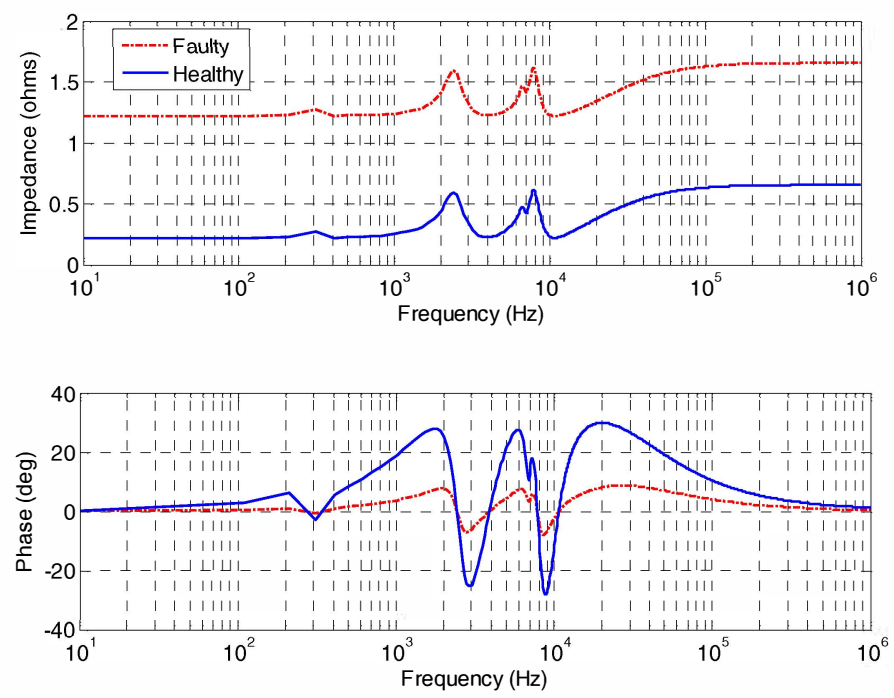

Fig. 18. DFIG Bode diagram with stator resistance variation.

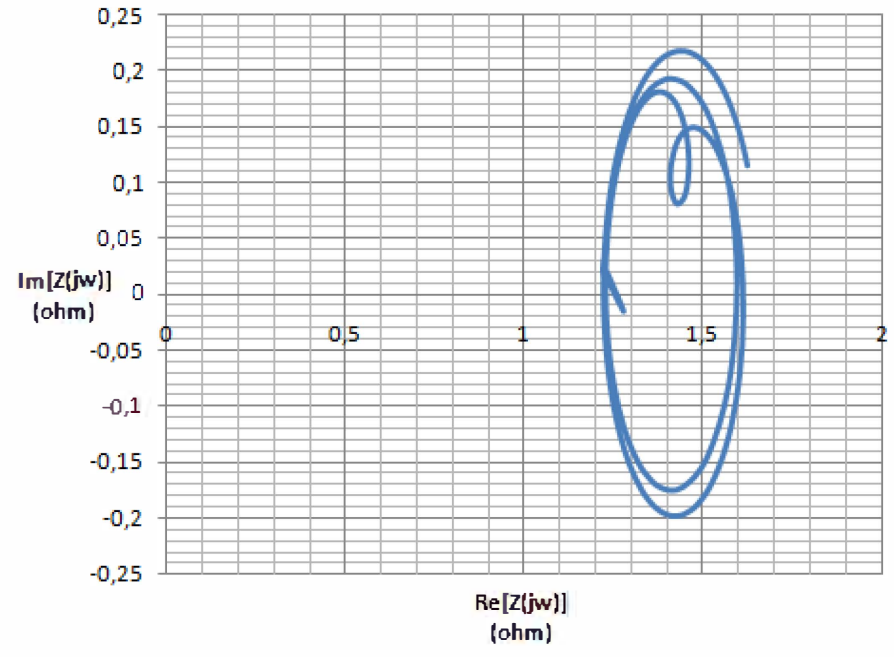

Fig. 19. DFIG Nyquist diagram with stator resistance variation.

\section{CONCLUSION}

This paper dealt with DFIG-base wind turbine failure diagnosis using impedance spectroscopy. This is a first attempt to evaluate impedance spectroscopy failure diagnosis performances. Characteristic Bode and Nyquist diagrams for frequent failures have shown that impedance spectroscopy allows having typical signatures and could be considered as a promising failure diagnosis tool.

\section{REFERENCES}

[1] Météo France, Average wind speed at $10 \mathrm{~m}$ height in France, ptcentre.net46.net

[2] Y. Amirat, M. Benbouzid, E. Al-Ahmar, B. Bensaker, and S. Turri, "A brief status on condition monitoring and fault diagnosis in wind energy conversion systems," Renewable and Sustainable Energy Reviews, vol. 13, no. 9, pp. 2629-2636, 2009.

[3] B. Lu, Y. Li, X. Wu and Z. Yang, "A review of recent advances in wind turbine condition monitoring and fault diagnosis", in Proceedings of the 2009 IEEE PEMWA, Lincoln (USA), pp. 1-7, June 2009.

[4] Y. Amirat, V. Choqueuse and M.E.H. Benbouzid, "Bearing fault detection in DFIG-based wind turbines using the first intrinsic mode function," in Proceedings of the 2010 IEEE IECON 2012, Montreal (Canada), pp. 1-6, October 2012.

[5] E.H. El Bouchikhi, V. Choqueuse, M.E.H. Benbouzid, J.F Charpentie and G. Barakat, "A comparative study of time-frequency representations for fault detection in wind turbine," in Proceedings of the 2011 IEEE IECON, Melbourne (Australia), pp. 3584-3589, November 2011.

[6] K. Rothenhagen and F.W. Fuchs, "Current sensor fault detection, isolation, and reconfiguration for doubly fed induction generators," IEEE Trans. Industrial Electronics, vol. 56, nº10, pp. 4239-4245, October 2009.

[7] The MathWorks, "SimPowerSystems for use with Simulink," User's Guide, 2012.

[8] P.W. Atkins, Physical Chemistry. Oxford University Press 1990

[9] J.R. Macdonald, "Impedance spectroscopy," Annals of Biomedical Engineering, vol. 20, pp. 289-305, 1992.

[10] E. Barsoukov and J.R. Macdonald, Impedance Spectroscopy: Theory, Experiment, and Application. Wiley Interscience Publications, 2005.

[11] A.J. Bard and L.R. Faulkner, Electrochemical Methods: Fundamentals and Applications. Wiley, Interscience Publications, 2000.

[12] M.J. Given, R.A. Fouracre, S.J. MacGregor, M. Judd and H.M. Banford, "Diagnostic dielectric spectroscopy methods applied to water-treed cable," IEEE Trans. Dielectrics and Electrical Insulation, vol. 8, n ${ }^{\circ} 6, \mathrm{pp}$ 917-920, December 2001. 